\title{
Overexpression of long non-coding RNA cancer susceptibility 11 is involved in the development of chemoresistance to carboplatin in hepatocellular carcinoma
}

\author{
HAIDONG LIU ${ }^{1 *}$, TAO LIU $^{2 *}$, YONG ZHOU ${ }^{2}$, XINWEN SONG ${ }^{3}$ and RENDONG WEI ${ }^{2}$ \\ Departments of ${ }^{1}$ Digestive Diseases and ${ }^{2}$ Hepatology, The Sixth People's Hospital of Qingdao, Qingdao, \\ Shandong 266033; ${ }^{3}$ Department of Infectious Diseases, The First Affiliated Hospital of \\ Xinxiang Medical University, Weihui, Henan 453100, P.R. China
}

Received November 15, 2018; Accepted November 13, 2019

DOI: $10.3892 / 01.2020 .11265$

\begin{abstract}
The long non-coding (lnc)RNA cancer susceptibility 11 (CASC11) promotes gastric cancer, however its role in other diseases is unknown. The present study demonstrated upregulation of IncRNA CASC11 and microRNA (miR)-21 in hepatocellular carcinoma (HCC). Furthermore, the expression of CASC11 was positively correlated with that of miR-21 in HCC tumors. Moreover, overexpression of lncRNA CASC11 led to upregulation of miR-21 in HCC cells, whereas overexpression of miR-21 had no effect on CASC11 levels. The levels of lncRNA CASC11 and miR-21 were found to be upregulated in the plasma of patients with HCC during chemotherapy. In vitro cell experiments demonstrated upregulation of lncRNA CASC11 in HCC cells treated with carboplatin. Additionally, overexpression of lncRNA CASC11 promoted, whereas its knockdown inhibited the viability of HCC cells following carboplatin treatment. Finally, overexpression of miR-21 ameliorated the effects of lncRNA CASC11 knockdown on cell viability. Thus, these findings suggest that upregulation of 1 ncRNA CASC11 is involved in the development of chemoresistance to carboplatin in patients with HCC, via the upregulation of miR-21.
\end{abstract}

\section{Introduction}

Liver cancer affects millions of patients and is associated with high incidence and mortality rates worldwide (1). In certain countries, such as the US, the incidence rate of liver cancer

Correspondence to: Dr Rendong Wei, Department of Hepatology, The Sixth People's Hospital of Qingdao, 9 Fushun Road, Qingdao, Shandong 266033, P.R. China

E-mail: p211145@163.com

*Contributed equally

Key words: hepatocellular carcinoma, long non-coding RNA cancer susceptibility 11, microRNA-21, viability has declined, whereas the mortality rate has increased (2). The clinical treatment of this disease is challenged by the high prevalence of cancer metastasis, lacking radical treatment options (3). Chemotherapy, such as the use of carboplatin, is widely applied to treat patients at advanced stages, however the development of drug resistance leads to poor outcomes $(4,5)$.

Non-coding RNAs exhibit diverse functions (6). MicroRNAs (miRNAs/miRs) and long non-coding (lnc)RNAs are two major subgroups of non-coding RNAs (ncRNAs). lncRNAs and miRNAs are essential players in human diseases, particularly in cancer $(7,8)$. It has been widely established that ncRNAs participate in cancer biology mainly by affecting cancer cell behaviors, such as proliferation, migration and the sensitivity to chemical drugs $(7,8)$. miR-21 has been found to promote the development of different types of cancer, including that of the liver $(9,10)$. The IncRNA cancer susceptibility 11 (CASC11) was found to promote gastric cancer (11). The role of these ncRNAs in hepatocellular carcinoma (HCC), a major subtype of liver cancer, was investigated in the present study. In this study, the expression of CASC11 and miR-21 in samples from patients with HCC was measured by reverse transcription-quantitative (RT-q)PCR. Overexpression experiments were performed to analyze the interaction between CASC11 and miR-21. MTT assay was used to analyze the effects of CASC11 and miR-21 expression on the viability of HCC cells upon carboplatin treatment. The findings of this study suggest that lncRNA CASC11 mediates the development of chemoresistance to carboplatin in patients with $\mathrm{HCC}$, via the upregulation of miR-21.

\section{Materials and methods}

Patients, tissues, treatments and cell lines. A total of 69 patients with advanced HCC, who were admitted to The Sixth People's Hospital of Qingdao, Qingdao, China, between September 2015 and May 2018, were enrolled. During biopsy, adjacent (5 $\mathrm{cm}$ around tumors) healthy and tumor tissues were collected from each participant. Blood $(5 \mathrm{ml})$ was also extracted from each patient using EDTA tubes before treatment under fasting conditions for the isolation of plasma. Inclusion criteria: i) Patients with expected survival time $>12$ months; 
ii) patients at advanced stage (stages III and IV), who were not suitable for surgical resection; and iii) patients who were treated with different doses of carboplatin according to their conditions. Exclusion criteria: i) Patients with other diseases; ii) patients who were treated before admission; iii) patients who failed to cooperate with researchers; and iv) patients who died during this study. Blood was also extracted under fasting conditions at 3 and 6 months after the beginning of carboplatin treatment to extract plasma. The patients included 38 males and 31 females, with a mean age of $48.2 \pm 5.1$ years (age range, 30-66 years). There were 38 patients at stage III and 31 patients at The American Joint Committee on Cancer stage IV (12). All patients signed informed consent. The Ethics Committee of The Sixth People's Hospital of Qingdao approved this study.

HCC cell lines SNU-398 and SNU-182 were purchased from American Type Culture Collection (ATCC). A mixture composed of 90\% RPMI 1640 medium (ATCC) and 10\% FBS (ATCC) was used to cultivate cells at $37^{\circ} \mathrm{C}$ in a $5 \% \mathrm{CO}_{2}$ incubator.

$R T-q P C R$. In order to detect CASC11, total RNA was extracted from in vitro cultivated cells, plasma and tissue sample using RNAzol ${ }^{\circledR}$ RT RNA Isolation reagent (GeneCopoeia,Inc.) and RT was performed using the Applied Biosystems ${ }^{\mathrm{TM}}$ High-Capacity cDNA Reverse Transcription kit (Thermo Fisher Scientific, Inc.), through the following conditions: $25^{\circ} \mathrm{C}$ for $10 \mathrm{~min}, 52^{\circ} \mathrm{C}$ for $20 \mathrm{~min}$ and $80^{\circ} \mathrm{C}$ for $10 \mathrm{~min}$. Mixtures for qPCR were prepared using the qScript One-Step RT-qPCR kit (Quantabio). In order to detect miR-21, the ReliaPrep ${ }^{\mathrm{TM}}$ miRNA Cell and Tissue Miniprep system (Promega Corporation) was used to extract miRNAs, the miScript II RT kit (Qiagen $\mathrm{GmbH}$ ) was used to carry out RT, and qPCR mixtures were prepared using the mirVana qRT-PCR miRNA Detection kit (Thermo Fisher Scientific, Inc.). All PCR reactions were performed on the ABI 7500 Real-Time PCR System (Thermo Fisher Scientific, Inc.). PCR conditions were: $95^{\circ} \mathrm{C}$ for $1 \mathrm{~min}$, followed by 40 cycles of $95^{\circ} \mathrm{C}$ for $10 \mathrm{sec}$ and $60^{\circ} \mathrm{C}$ for $45 \mathrm{sec}$. Primers of lncRNA CASC11, miR-21, and endogenous controls GAPDH and U6 were obtained from Sangon Biotech Co., Ltd. CASC11 forward, 5'-GGACACCAACTATTGCTTCA-3' and reverse, 5'-TCC AGGCTCCAAATGTAG-3'; GAPDH forward, 5'-GTCTCC TCTGACTTCAACAGC-3' and reverse, 5'-ACCACCCTGTTG CTGTAGCCA-3'; miR-21 forward, 5'-TAGCTTATCAGACTG ATG-3' and reverse primer (universal primer) and U6 primers were from the RT-qPCR miRNA Detection kit (Thermo Fisher Scientific, Inc.). According to the $2^{-\Delta \Delta \mathrm{Cq}}$ method (13) of quantification, lncRNA CASC11 expression was normalized to that of GAPDH and miR-21 expression was normalized to that of U6.

Transient transfection. IncRNA CASC11 overexpression vectors and empty vectors, as well as lncRNA CASC11 small interfering (si)RNA (5'-UUCUUCACCACCUCC AGUUGC-3') and negative control siRNA (5'-UGAACG UACGGGCAUGUCAGC-3') were purchased from Sangon Biotech Co., Ltd. Negative miRNA control (5'-UGAACG UACGGGCAUGUCAGC-3') and miR-21 mimic (5'-UAG CUUAUCAGACUGAUGUUGA-3') were purchased from Sigma-Aldrich; Merck KGaA. Lipofectamine ${ }^{\circledR} 2000$ reagent (cat. no. 11668-019; Invitrogen; Thermo Fisher Scientific, Inc.) was used to transfect $1 \times 10^{6}$ SNU-398 and SNU-182 cells in each well of a 6-well cell culture plate ( $2 \mathrm{ml}$ medium per well) with vectors at a dose of $10 \mathrm{nM}$ and siRNA or miRNA at a dose of $35 \mathrm{nM}$. The duration of incubation with transfection reagent and vector was $6 \mathrm{~h}$. Cells without transfections were considered as the control cells. The expression of CASC11 and miR-21 was detected by RT-qPCR. Subsequent experiments were performed $48 \mathrm{~h}$ later.

MTT assay. Cells were harvested for an MTT assay when the overexpression rates of 1ncRNA CASC11 and miR-21 reached $200 \%$ and the lncRNA CASC11 knockdown rate reached $50 \%$. Briefly, cell suspensions were prepared and cell density was adjusted to $3 \times 10^{4}$ cells $/ \mathrm{ml}$. Cells suspensions were transferred to a 96 -well plate $(0.1 \mathrm{ml} /$ well $)$. Carboplatin $\left[\mathrm{C}_{4} \mathrm{H}_{6}\left(\mathrm{CO}_{2}\right)_{2} \mathrm{Pt}\left(\mathrm{NH}_{3}\right)_{2}\right.$; Sigma-Aldrich; Merck KGaA] was added at doses of $200 \mu \mathrm{g} / \mathrm{ml}$ at $4 \mathrm{~h}$ after seeding. Cells were cultured under normal conditions $\left(37^{\circ} \mathrm{C}, 5 \% \mathrm{CO}_{2}\right)$ for $24 \mathrm{~h}$, followed by the addition of MTT (10 $\mu \mathrm{l} /$ well). Cells were cultured for an additional $4 \mathrm{~h}$, followed by the addition of DMSO $10 \mu \mathrm{l} /$ well) and the measurement of optical density values at $570 \mathrm{~nm}$.

Statistical analysis. The values of the mean \pm SD were calculated from data of 3 biological replicates. Pearson's correlation analysis was performed to analyze the correlation between CASC11 and miR-21 levels. Comparisons of lncRNA CASC11 and miR-21 expression levels between two different types of tissues were performed with paired Student's t-test. Comparisons among multiple groups were carried out using one-way ANOVA and Tukey's post hoc test. Any difference with a $\mathrm{P}<0.05$ was considered to be statistically significant.

\section{Results}

lncRNA CASC11 and miR-21 levels are upregulated in HCC. Expression of IncRNA CASC11 and miR-21 was detected by RT-qPCR. Compared with those in adjacent healthy tissues, the expression levels of CASC11 (Fig. 1A) and miR-21 (Fig. 1B) were significantly higher in tumor tissues (both $\mathrm{P}<0.05$ ).

HCC tumor expression levels of CASC11 and miR-21 are positively correlated. Pearson's correlation analysis was performed to assess the correlation between the expression levels of lncRNA CASC11 and miR-21 in tumor tissues and adjacent healthy tissues. As shown in Fig. 2A, the expression levels of lncRNA CASC11 and miR-21 were significantly and positively correlated in tumor tissues $(\mathrm{P}<0.001)$. In contrast, the expression levels of these molecules were not correlated in adjacent healthy tissues ( $\mathrm{P}=0.76$; Fig. 2B).

IncRNA CASC11 functions as an upstream activator of miR-21 in HCC cells. In vitro overexpression experiments were performed to further investigate the association between lncRNA CASC11 and miR-21 in HCC cell lines. Compared with the control and negative control groups, the overexpression of lncRNA CASC11 led to upregulation of miR-21 in SNU-398 and SNU-182 cells (Fig. 3A; all P<0.05). In contrast, the overexpression of miR-21 had no significant effect on the expression of lncRNA CASC11 in these cells (Fig. 3B; all $\mathrm{P}>0.05)$. 
A

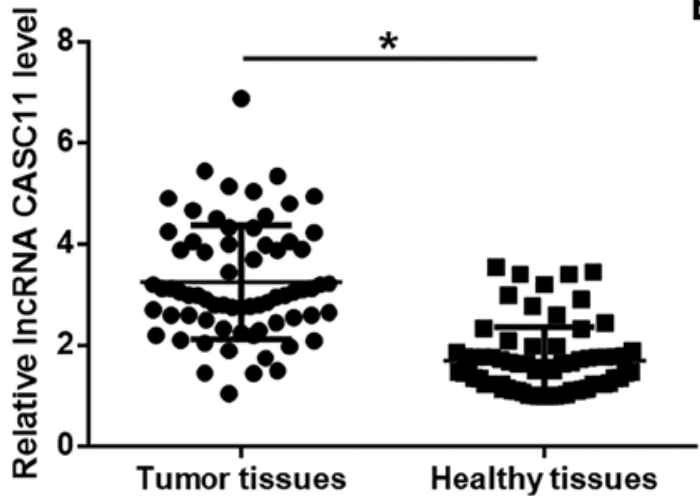

B

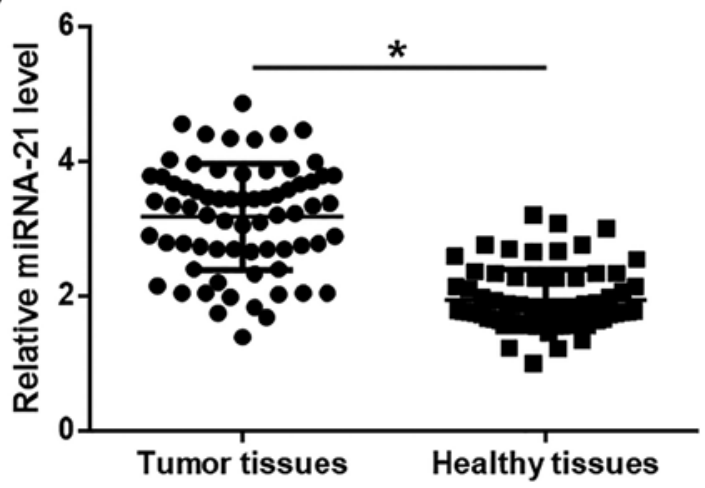

Figure 1. IncRNA CASC11 and miR-21 are upregulated in clinical HCC tumor samples. Reverse transcription-quantitative PCR results showed significantly increased expression levels of (A) lncRNA CASC11 and (B) miR-21 in tumor samples compared with adjacent healthy tissues. * $<0.05$. IncRNA, long non-coding RNA; miR, microRNA; CASC11, cancer susceptibility 11.
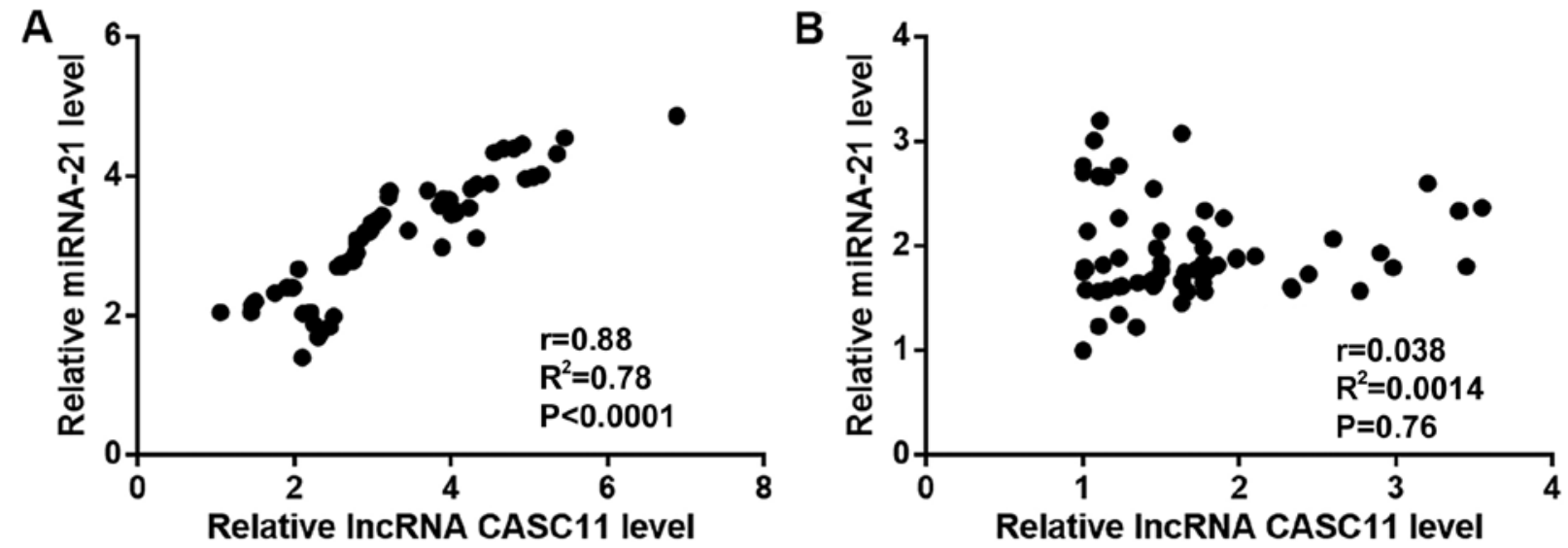

Figure 2. Expression levels of 1ncRNA CASC11 and miR-21 are positively correlated in hepatocellular carcinoma tumors. Pearson's correlation analysis demonstrated a positive correlation between the expression levels of lncRNA CASC11 and miR-21 in (A) tumor tissues, unlike in adjacent healthy tissues (B). lncRNA, long non-coding RNA; miR, microRNA; CASC11, cancer susceptibility 11.

Plasma levels of IncRNA CASC11 and miR-21 are upregulated during chemotherapy. The plasma levels of IncRNA CASC11 and miR-21 were detected by RT-qPCR at three time-points, including before treatment and at 3 and 6 months after treatment with carboplatin. The plasma levels of lncRNA CASC11 (Fig. 4A) and miR-21 (Fig. 4B) were significantly increased at 3 and 6 months after treatment (all $\mathrm{P}<0.05)$, compared with the levels before treatment. The plasma levels of lncRNA CASC11 (Fig. 4A) and miR-21 (Fig. 4B) were also significantly higher at 6 months after treatment (both $\mathrm{P}<0.05$ ), compared with the levels at 3 months.

Carboplatin treatment upregulates IncRNA CASC11 expression in HCC cells. SNU-398 and SNU-182 cells were treated with 50,100 and $200 \mu \mathrm{g} / \mathrm{ml}$ carboplatin for $24 \mathrm{~h}$, followed by the detection of lncRNA CASC11 expression by RT-qPCR. As shown in Fig. 5, carboplatin treatment resulted in a dose-dependent upregulation of CASC11 in these cells.

IncRNA CASC11 promotes carboplatin-treated HCC cell viability via $m i R-21$. The cell viability assay was performed under carboplatin treatment only $(200 \mu \mathrm{g} / \mathrm{ml})$. It is a limitation of this study that the cell viability assay was performed only under conditions of carboplatin treatment and no-treatment controls were not included. Overexpression of lncRNA CASC11 and miR-21 promoted, whereas lncRNA CASC11 knockdown inhibited, the viability of carboplatin-treated HCC cells, compared with the control groups (all $\mathrm{P}<0.05$ ). In addition, miR-21 overexpression attenuated the effects of lncRNA CASC11 knockdown on cell viability $(\mathrm{P}<0.05$; Fig. 6).

\section{Discussion}

CASC11 was demonstrated to be an oncogenic lncRNA in gastric cancer (11). The key finding of the present study was that lncRNA CASC11 was overexpressed in HCC, and participates in the development of chemoresistance to carboplatin in patients with HCC, via the upregulation of miR-21.

Development of chemoresistance is common during clinical treatment of liver cancer, providing a major challenge for clinical management (14). miR-21, as an oncogenic miRNA, is upregulated in certain types of cancer in humans, including HCC (15). In the present study, upregulation of miR-21 was observed in HCC tissues compared with healthy tissues. Besides its involvement in cancer development, the 

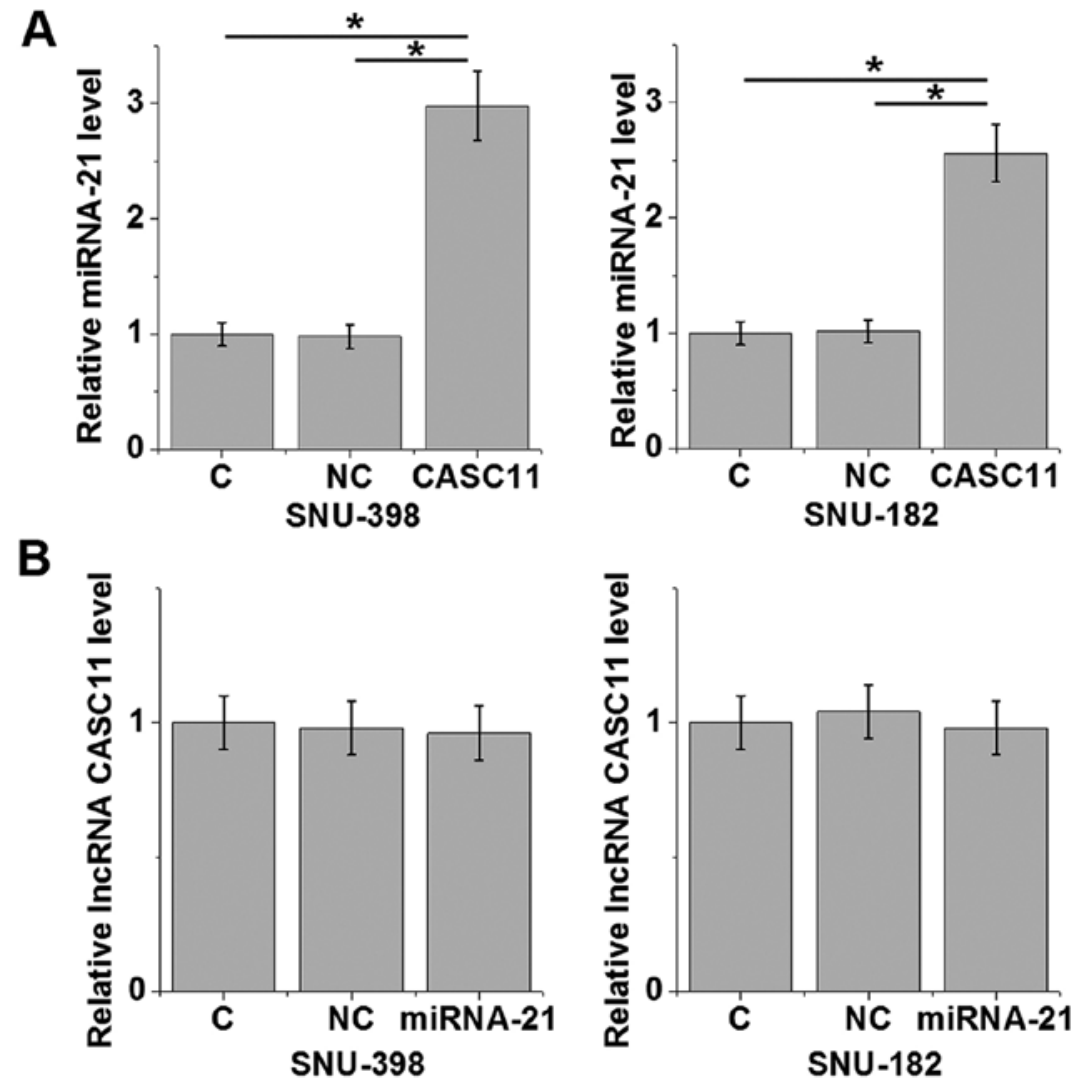

Figure 3. lncRNA CASC11 serves as an upstream activator of miR-21 in hepatocellular carcinoma cell lines. (A) Overexpression of lncRNA CASC11 led to upregulation of miR-21 in SNU-398 and SNU-182 cells. (B) In contrast, overexpression of miR-21 had no significant effect on the expression of lncRNA CASC11 in these cells. " $\mathrm{P}<0.05$. IncRNA, long non-coding RNA; miR, microRNA; CASC11, cancer susceptibility 11; C, control; NC, negative control.

A

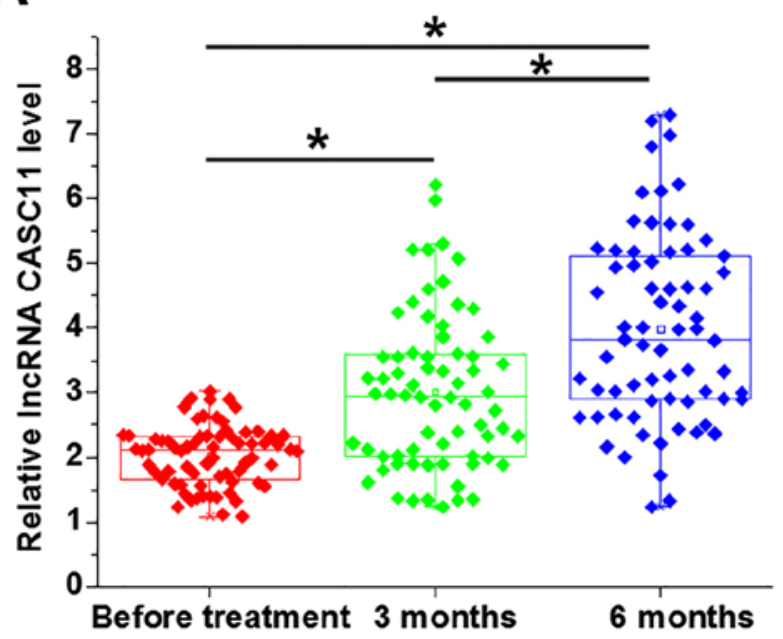

B

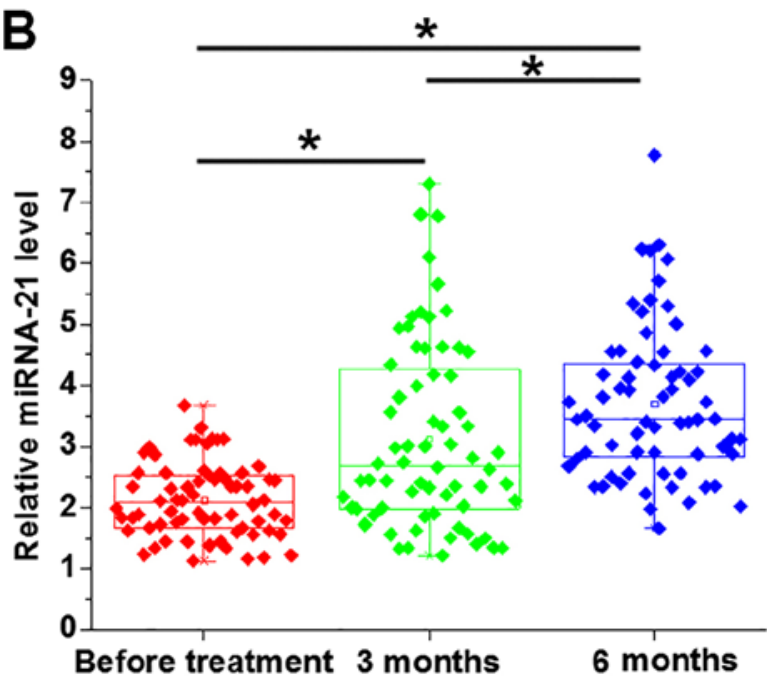

Figure 4. Plasma levels of lncRNA CASC11 and miR-21 are upregulated during chemotherapy with carboplatin in patients with hepatocellular carcinoma. Reverse transcription-quantitative PCR analysis demonstrated significant increase in plasma (A) lncRNA CASC11 and (B) miR-21 levels during chemotherapy with carboplatin compared with levels before treatment. ${ }^{*} \mathrm{P}<0.05$. lncRNA, long non-coding RNA; miR, microRNA; CASC11, cancer susceptibility 11.

expression of miR-21 also determined the chemosensitivity of cancer cells to chemotherapy (16). In the present study, upregulation of miR-21 was observed in patients with HCC who underwent carboplatin treatment. In addition, miR-21 overexpression promoted the viability of carboplatin-treated HCC cells cultured in vitro. Therefore, miR-21 appears to inhibit the chemosensitivity of HCC cells to carboplatin.
The development of chemoresistance in certain cases also requires the involvement of IncRNAs $(17,18)$. In the present study the upregulation of lncRNA CASC11 was demonstrated in $\mathrm{HCC}$, indicating its oncogenic role. Further investigation revealed the role of lncRNA CASC11 in chemoresistance to carboplatin in HCC. Therefore, inhibition of lncRNA CASC11 may serve as a potential therapeutic target. However, further 

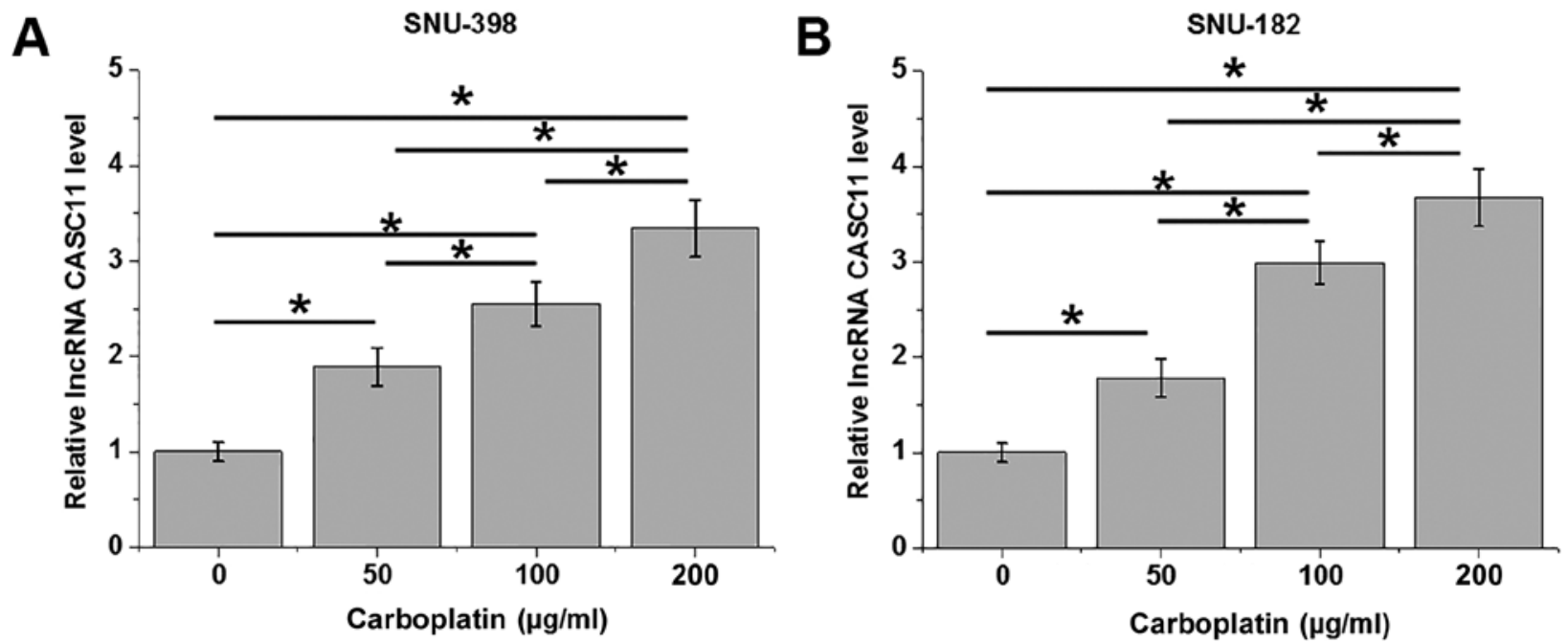

Figure 5. Carboplatin treatment upregulates lncRNA CASC11 expression in hepatocellular carcinoma cell lines. Carboplatin treatment resulted in upregulation of IncRNA CASC11 expression in (A) SNU-398 and (B) SNU-182 cells, in a dose-dependent manner. " $\mathrm{P}<0.05$. IncRNA, long non-coding RNA; miR, microRNA; CASC11, cancer susceptibility 11.
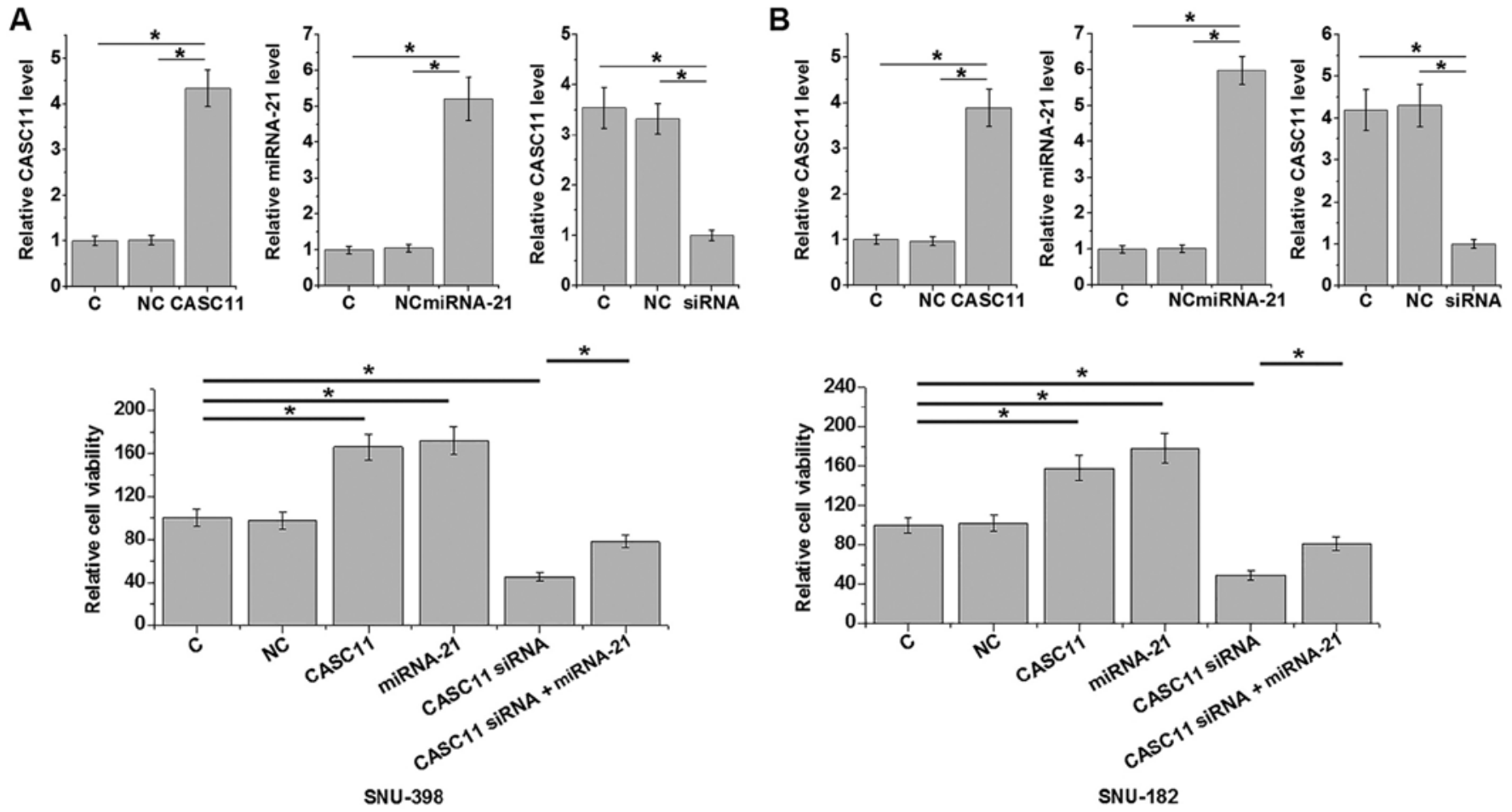

Figure 6. IncRNA CASC11 promotes hepatocellular carcinoma cell viability following carboplatin treatment, through miR-21. Reverse transcription-quantitative analysis confirmed overexpression of lncRNA CASC11, overexpression of miR-21 and knockdown of CASC11 in (A, top panel) SNU-398 and (B, top panel) SNU-182 cells transfected with CASC11 overexpression vector, miR-21 mimic and CASC11 siRNA, respectively. An MTT assay in (A, bottom panel) SNU-398 and (B, bottom panel) SNU-182 cells demonstrated that overexpression of lncRNA CASC11 promoted, whereas lncRNA CASC11 knockdown inhibited the viability of HCC cells following carboplatin treatment. In addition, miR-21 overexpression attenuated the effects of IncRNA CASC11 knockdown on cell viability. Only the empty vector NC group was present as the values of the overexpression NC, miR mimic NC, siRNA NC and the NC for the siRNA+mimic combination groups showed similar values, and so, to simplify the comparisons, all groups were compared with $\mathrm{C}$ group. " $\mathrm{P}<0.05$. $\mathrm{C}$, control cells without transfection; NC, negative control; lncRNA, long non-coding RNA; miRNA, microRNA; CASC11, cancer susceptibility 11; siRNA, small interfering RNA.

in vitro and in vivo studies and clinical trials are required to support this conclusion.

Associations between miRNAs and lncRNAs are frequently observed during the development of cancer $(19,20)$. The present study demonstrated lncRNA CASC11 as a likely upstream activator of miR-21 in HCC. In addition, this association was suggested to be involved in the development of resistance to carboplatin in patients. These findings provide new insights into the mechanism of the development of chemoresistance in patients with HCC. However, the molecular mechanism mediating the interaction between CASC11 and miR-21 is unknown. A study by Zhang et al (21) reported the interac- 
tion of CASC11 with WNT/ $\beta$-catenin to promote colorectal cancer. Moreover, it is known that miR-21 can interact with WNT/ $\beta$-catenin (22). Therefore, WNT/ $\beta$-catenin may mediate the interaction between CASC11 and miR-21. In addition, CASC11 and miR-21 may regulate the viability of HCC cells, following carboplatin treatment, via the multidrug resistance gene, P-glycoprotein, and multidrug resistance-associated proteins that improve the viability of cancer cells undergoing chemotherapies. However, preliminary data demonstrated that the multidrug resistance 1 gene (P-glycoprotein 170) and multidrug resistance-associated proteins 1-3 did not respond to CASC11 overexpression (unpublished data). Thus, future studies will explore the involvement of other genes.

In conclusion, the data suggest that lncRNA CASC11 and miR-21 are overexpressed in HCC and that lncRNA CASC11 participates in the development of chemoresistance to carboplatin in patients with HCC, mediated by the upregulation of miR-21.

\section{Acknowledgements}

Not applicable.

\section{Funding}

No funding was received.

\section{Availability of data and materials}

The datasets used and/or analyzed during the current study are available from the corresponding author on reasonable request.

\section{Authors' contributions}

HL, TL and RW designed the experiments. HL and TL performed the experiments. YZ and XS collected and analyzed the data. RW drafted the manuscript. All authors approved the final version of this manuscript.

\section{Ethics approval and consent to participate}

This study was approved by the Ethics Committee of the Sixth People's Hospital of Qingdao (Qingdao, China). All participants provided written informed consent.

\section{Patient consent for publication}

Not applicable.

\section{Competing interests}

The authors declare that they have no competing interests.

\section{References}

1. Ryerson AB, Eheman CR, Altekruse SF, Ward JW, Jemal A Sherman RL, Henley SJ, Holtzman D, Lake A, Noone AM, et al: Annual Report to the Nation on the Status of Cancer, 1975-2012, featuring the increasing incidence of liver cancer. Cancer 122: 1312-1337, 2016.
2. Altekruse SF, Henley SJ, Cucinelli JE and McGlynn KA: Changing hepatocellular carcinoma incidence and liver cancer mortality rates in the United States. Am J Gastroenterol 109: 542-553, 2014.

3. Wang $\mathrm{H}$ and Chen L: Tumor microenviroment and hepatocellular carcinoma metastasis. J Gastroenterol Hepatol 28 (Suppl 1): S43-S48, 2013.

4. Lee MH, Kim EJ, Lee H, Kim HM, Chang MJ, Park SY, Hong KS, Kim JS and Sessler JL: Liposomal texaphyrin theranostics for metastatic liver cancer. J Am Chem Soc 138: 16380-16387, 2016.

5. Zhao X, Chen Q, Liu W, Li Y, Tang H, Liu X and Yang X: Codelivery of doxorubicin and curcumin with lipid nanoparticles results in improved efficacy of chemotherapy in liver cancer. Int J Nanomedicine 10: 257-270, 2015.

6. Esteller M: Non-coding RNAs in human disease. Nat Rev Genet 12: 861-874, 2011.

7. Spizzo R, Almeida MI, Colombatti A and Calin GA: Long non-coding RNAs and cancer: A new frontier of translational research? Oncogene 31: 4577-4587, 2012.

8. Calin GA and Croce CM: MicroRNA signatures in human cancers. Nat Rev Cancer 6: 857-866, 2006.

9. Kumarswamy R, Volkmann I and Thum T: Regulation and function of miRNA-21 in health and disease. RNA Biol 8: 706-713, 2011.

10. Pan X, Wang ZX and Wang R: MicroRNA-21: a novel therapeutic target in human cancer. Cancer Biol Ther 10: 1224-1232, 2010.

11. Zhang L, Kang W, Lu X, Ma S, Dong L and Zou B: lncRNA CASC11 promoted gastric cancer cell proliferation, migration and invasion in vitro by regulating cell cycle pathway. Cell Cycle 17: 1886-1900, 2018.

12. Chun YS, Pawlik TM and Vauthey JN: 8th Edition of the AJCC cancer staging manual: Pancreas and hepatobiliary cancers. Ann Surg Oncol 25: 845-847, 2018.

13. Livak KJ and Schmittgen TD: Analysis of relative gene expression data using real-time quantitative PCR and the 2(-Delta Delta C(T)) method. Methods 25: 402-408, 2001.

14. Briz O, Perez MJ and Marin JJ: Further understanding of mechanisms involved in liver cancer chemoresistance. Hepatoma Res 3: 22-26, 2017.

15. Mao B, Xiao H, Zhang Z, Wang D and Wang G: MicroRNA-21 regulates the expression of BTG2 in HepG2 liver cancer cells. Mol Med Rep 12: 4917-4924, 2015.

16. Wei J, Gao W, Zhu CJ, Liu YQ, Mei Z, Cheng T and Shu YQ: Identification of plasma microRNA-21 as a biomarker for early detection and chemosensitivity of non-small cell lung cancer. Chin J Cancer 30: 407-414, 2011.

17. Si X, Zang R, Zhang E, Liu Y, Shi X, Zhang E, Shao L, Li A, Yang N, Han X, et al: lncRNA H19 confers chemoresistance in $E R \alpha$-positive breast cancer through epigenetic silencing of the pro-apoptotic gene BIK. Oncotarget 7: 81452-8146, 2016.

18. Shen CJ, Cheng YM and Wang CL: IncRNA PVT1 epigenetically silences miR-195 and modulates EMT and chemoresistance in cervical cancer cells. J Drug Target 25: 637-644, 2017.

19. Zhou X, Ye F, Yin C, Zhuang Y, Yue G and Zhang G: The interaction between miR-141 and lncRNA-H19 in regulating cell proliferation and migration in gastric cancer. Cell Physiol Biochem 36: 1440-1452, 2015.

20. Cao MX, Jiang YP,Tang YL and Liang XH: The crosstalk between IncRNA and microRNA in cancer metastasis: Orchestrating the epithelial-mesenchymal plasticity. Oncotarget 8: 12472-12483, 2017.

21. Zhang Z, Zhou C, Chang Y, Zhang Z, Hu Y, Zhang F, Lu Y, Zheng L, Zhang W, Li X and Li X: Long non-coding RNA CASC11 interacts with hnRNP-K and activates the WNT/ $\beta$-catenin pathway to promote growth and metastasis in colorectal cancer. Cancer Lett 376: 62-73, 2016.

22. Wu D, Shi $M$ and Fan XD: Mechanism of miR-21 via Wnt/ $\beta$-catenin signaling pathway in human A549 lung cancer cells and Lewis lung carcinoma in mice. Asian Pac J Trop Med 8: 479-484, 2015. 